\title{
Urogenital schistosomiasis transmission on Unguja Island, Zanzibar: characterisation of persistent hot-spots
}

Tom Pennance ${ }^{1,2}$, Bobbie Person ${ }^{3}$, Mtumweni Ali Muhsin ${ }^{4}$, Alipo Naim Khamis ${ }^{4}$, Juma Muhsin ${ }^{4}$, Iddi Simba Khamis ${ }^{4}$, Khalfan Abdallah Mohammed ${ }^{4}$, Fatma Kabole ${ }^{4}$, David Rollinson ${ }^{1}$ and Stefanie Knopp ${ }^{1,5,6^{*}}$

\begin{abstract}
Background: Elimination of urogenital schistosomiasis transmission is a priority for the Zanzibar Ministry of Health. Preventative chemotherapy together with additional control interventions have successfully alleviated much of the disease burden. However, a persistently high Schistosoma haematobium prevalence is found in certain areas. Our aim was to characterise and evaluate these persistent "hot-spots" of transmission and reinfection in comparison with low-prevalence areas, to support the intervention planning for schistosomiasis elimination in Zanzibar.

Methods: Prevalences of $S$. haematobium were annually determined by a single urine filtration in schoolchildren from 45 administrative areas (shehias) in Unguja in 2012, 2013 and 2014. Coverage data for biannual treatment with praziquantel were available from ministerial databases and internal surveys. Among the 45 shehias, five hot-spot ( $\geq 15 \%$ prevalence) and two low-prevalence $(\leq 5 \%)$ shehias were identified and surveyed in mid-2014. Humanwater contact sites (HWCSs) and the presence of S. haematobium-infected and uninfected Bulinus globosus, as well as safe water sources (SWSs) and their reliability in terms of water availability were determined and mapped.

Results: We found no major difference in the treatment coverage between persistent hot-spot and low-prevalence shehias. On average, there were considerably more HWCSs containing B. globosus in hot-spot than in low-prevalence shehias ( $n=8$ vs $n=2$ ) and also more HWCSs containing infected B. globosus ( $n=2$ vs $n=0)$. There was no striking difference in the average abundance of SWSs in hot-spot and low-prevalence shehias $(n=45 \mathrm{vs} n=38)$ and also no difference when considering SWSs with a constant water supply (average: $62 \%$ vs $62 \%$ ). The average number of taps with a constant water supply, however, was lower in hot-spot shehias ( $n=7$ vs $n=14)$. Average distances from schools to the nearest HWCS were considerably shorter in hot-spot shehias ( $n=229 \mathrm{~m}$ vs $n=722 \mathrm{~m}$ ).

Conclusion: The number of HWCSs, their infestation with B. globosus and their distance to schools seem to play a major role for a persistently high S. haematobium prevalence in children. In addition to treatment, increasing access to reliably working taps, targeted snail control at HWCSs near schools and enhanced behaviour change measures are needed to reduce prevalences in hot-spot areas and to finally reach elimination.
\end{abstract}

Trial registration: ISRCTN48837681.

Keywords: Bulinus globosus, Cercariae, Control, Elimination, Hot-spot, Schistosoma haematobium, Snail, Safe water, Urogenital schistosomiasis, Zanzibar

\footnotetext{
* Correspondence: s.knopp@unibas.ch

'Wolfson Wellcome Biomedical Laboratories, Department of Life Sciences,

Natural History Museum, Cromwell Road, London SW7 5BD, UK

${ }^{5}$ Swiss Tropical and Public Health Institute, Socinstrasse 57, P.O. BoxCH-4002

Basel, Switzerland

Full list of author information is available at the end of the article
} 


\section{Background}

Historically, the Zanzibar islands (Unguja and Pemba) that are part of the United Republic of Tanzania have been identified as 'model islands' for implementing and assessing the effectiveness of multiple infectious disease control and elimination programmes in sub-Saharan Africa. For example, due to successful control efforts over the past decades, the number of malaria cases has drastically declined [1,2], the Tsetse fly has disappeared [3], and the transmission of lymphatic filariasis has been reduced to very low levels $[4,5]$. Also urogenital schistosomiasis that imposed a considerable public health problem and formerly occurred with a very high prevalence on both islands [6-11], is now targeted for elimination [12-14].

In 2011, the Zanzibar Elimination of Schistosomiasis Transmission (ZEST) alliance was formed to work towards the elimination of urogenital schistosomiasis [12]. Moreover, in 2012, the World Health Organization (WHO) set the goal to interrupt transmission of schistosomiasis in selected countries of the African region by 2025 [15], and Zanzibar has been mentioned as a place where concerted efforts for elimination have begun [16]. Since 2012, the Zanzibar Ministry of Health has been carrying out biannual preventive chemotherapy (PC) assisted by the Schistosomiasis Control Initiative (SCI) and WHO. To address research questions related to the elimination of urogenital schistosomiasis on Zanzibar, an operational research project supported by the Schistosomiasis Consortium for Operational Research and Evaluation (SCORE) has been implemented in selected communities on Unguja and Pemba islands since November 2011 [12, 13]. The cluster randomized trial has three study arms to assess the impact of (i) biannual PC, (ii) biannual PC plus snail control, and (iii) biannual PC plus behaviour change interventions, respectively, on Schistosoma haematobium prevalences and infection intensities [13].

The baseline parasitological survey conducted within the SCORE operational research trial revealed an overall S. haematobium prevalence of $7 \%$ and $4 \%$, in the school-aged and adult communities in Zanzibar, respectively [14]. Mean infection intensities at baseline were 5 eggs and 0.7 eggs in $10 \mathrm{ml}$ urine, respectively. Despite these very low overall endemicity levels, some communities with a considerably higher prevalence (up to $32 \%$ ) were identified at baseline [14]. In 2014, after all interventions had been implemented for two years, some of these communities had maintained a persistently high or even increasing prevalence, signifying high levels of ongoing transmission and reinfection, and thus referred to here as "persistent hot-spot" areas.

Persistent hot-spots following control strategies for schistosomiasis have been identified not only on Zanzibar $[6,10,17,18]$ but also in other countries such as Morocco
[19], Kenya [20-22] and China [23]. Multiple factors that can significantly increase the risk of infection with schistosomes might be important drivers for the existence and persistence of schistosomiasis transmission hot-spot areas and their resilience to PC and other intervention measures such as snail control and health education. These risk factors include living in close proximity to a freshwater body containing intermediate host snail species [17, 21, 24], frequent and intense contact of humans with natural freshwater [17, 25], lack of drinking water sources and latrines in schools [25] and the construction of agricultural water schemes [26]. Also "super-spreaders", potentially untreated or treated and then re-infected people that harbour heavy infections, might contribute to the perpetuation or resurgence of transmission [27, 28].

To target control interventions adequately, to reduce the prevalence and infection intensity in all areas and to finally reach elimination of urogenital schistosomiasis transmission across Zanzibar, key factors contributing to the persistence of hot-spots need to be identified. In the study presented here we aimed (i) to identify persisting S. haematobium transmission hot-spots and compare them with low-prevalence areas according to prevalence data obtained in the annual parasitological surveys of the SCORE project carried out in 2012, 2013 and 2014 (ii) to locate, map and count human-water contact sites (HWCSs) and safe water sources (SWSs) in selected persistent hot-spot and low-prevalence areas, (iii) to collect intermediate host snails (Bulinus globosus) from surveyed HWCSs, to 'shed' them (i.e. induce cercarial emergence) under laboratory conditions and to determine the prevalence of $S$. haematobium infections in snails at each HWCS, and (iv) to compare features of persistent hot-spot and low-prevalence areas to better target future interventions.

\section{Methods \\ Study area and population}

Unguja island, where this work was conducted, is divided into six districts that are further divided into 210 smaller administrative areas [29], referred to as shehias. A community leader, the sheha, locally governs each shehia. On Unguja, the average area of a shehia is $9.5 \mathrm{~km}^{2}$. A shehia can contain several villages, which can vary in population size and household number.

Transmission of urogenital schistosomiasis on Unguja is geographically restricted by the presence of the intermediate host snail species B. globosus, which is only found in the northern, western and central parts of the island but not in the South $[30,31]$. Our study hence focussed on shehias located in areas, where B. globosus is endemic [32].

The study was conducted in June and July 2014, coinciding with the tail end of the long rainy season (Masika 
rains), which usually lasts from March till June. Hence, during the study period, heavy rain was rare and day temperatures were moderate at $23-28{ }^{\circ} \mathrm{C}$.

Selection criteria for hot-spot and low-prevalence shehias Among the 45 shehias included in the SCORE project on Unguja [13], all shehias with a $S$. haematobium infection prevalence of $\geq 15 \%$ in 9-12 year-old schoolchildren in at least one of the three cross-sectional parasitological surveys conducted in primary schools of the shehias in 2012, 2013 and 2014, respectively, were considered as persistent hot-spots. Shehias with a prevalence of $\leq 5 \%$ in schoolchildren in all three parasitological surveys were considered as low-prevalence shehias. For operational reasons, a rigorous mapping exercise and snail survey was only feasible in a limited number of areas. Hence, shehias were further selected based on their attribution to intervention arms in the SCORE study and based on their location and geography.

\section{Collection and examination of urine samples within the SCORE study}

The S. haematobium prevalence in children aged 9-12 years is monitored annually in the 45 study schools on Unguja as part of the SCORE project [13]. Prior to the beginning of this study, parasitological surveys had been conducted in 2012, 2013 and 2014. Details of the survey procedure, selection and randomization of children and examination of urine samples for $S$. haematobium infection in the laboratory are described in detail in the published study protocol [13].

\section{Assessment of praziquantel treatment and coverage}

In an effort to eliminate urogenital schistosomiasis in Zanzibar, the whole eligible population on Unguja and Pemba, with the exception of children below the age of three years, pregnant women and severely sick persons, is treated biannually with praziquantel since April 2012 [33]. Hence, before the implementation of this study in June and July 2014, four community-wide treatment (CWT) rounds had been conducted by the Zanzibar Ministry of Health in April and November 2012 and in June and November 2013. In November 2013, children attending primary schools were supposed to receive praziquantel in their school and not in their community.

Coverage for every CWT round was reported by the Zanzibar Ministry of Health, which collected records from community drug distributors (CDDs). Coverage for the school-based treatment (SBT) round was reported by the Ministry of Health in line with records provided by the schoolteachers and its own staff. Moreover, a post-treatment survey was conducted within the SCORE study for the CWT and SBT rounds that were conducted in November 2013 [33].

\section{Identification and characterization of HWCSs}

Several types of HWCSs occur in Unguja: ponds (defined as a small standing body of water), rivers (defined as a water body with a current that leads to a lake or the sea), streams (defined as body of water with a current that eventually joins to a river) and rice paddies (defined as flooded piece of land used for cultivating semiaquatic rice). All of these HWCSs can potentially act as suitable environments for B. globosus [34]. Human-water contact sites were defined as points where people can gain access to open freshwater bodies. The sites were located with the help of the sheha, assistant sheha, or any village member familiar with the geography of the shehia and mapped with a handheld Garmin GPSMAP 62sc device (Garmin, Kansas City, USA). Each HWCS was investigated for the presence of intermediate host snails as described below. Moreover, physical and chemical water characteristics (temperature, $\mathrm{pH}$, conductivity and total dissolved solids) of the HWCSs and ecological characteristics such as substrates and vegetation were assessed and recorded as described elsewhere in more detail [13]. Additionally and as part of the HWCS characterisation, human activities that bear a risk for S. haematobium infection and transmission (e.g. swimming and washing clothes) were determined by observation of evidence and recorded.

\section{Collection of intermediate host snails}

At each identified HWCS, a snail survey was conducted aiming to identify all snail species present and to specifically collect Bulinus snails. At each identified site, two collectors searched for snails of all species for $15 \mathrm{~min}$ and over no more than a $15 \mathrm{~m}^{2}$ area. Borders of the water body and vegetation, where snails were most likely to be found, were more intensively searched than other areas. In rivers and streams snail collectors moved upand downstream from the access point whenever possible to target slow flowing regions that provide a more suitable environment for snails [35]. Snails were primarily searched for by hand, but a snail scoop was also used to reach under deeper vegetation or sites with restricted access. All snails were identified to at least the genus level, but only B. globosus and B. forskalii were removed from HWCSs, placed in screw top plastic containers with freshwater from the site and taken to the laboratory for cercariae shedding. The snail species and additional information about the habitat, such as vegetation and foliage at the site, was recorded. Snail collections were only conducted on clear days, as rain before collection times could affect the positioning of snails in the water and alter the 'catch' size.

\section{Cercariae shedding and collection}

All collected Bulinus snails were examined for cercariae shedding in the laboratory of the Zanzibar Neglected 
Tropical Diseases Programme in Zanzibar Town. Snails were examined following methods described by Allan et al. [35]. Cercariae of S. haematobium were identified by an experienced microscopist and transferred onto a Whatman FTA card (Whatman, Part of GE Healthcare, Florham Park, USA) for long term deoxyribonucleic acid (DNA) storage using a micropipette $(20 \mu \mathrm{l}$ Gilson PIPETMAN Classic, Gilson Inc, Wisconsin, USA) set to $3.5 \mu$ l. The FTA card was labelled with collection details and stored at the Schistosomiasis Collection at the Natural History Museum (SCAN) in London, UK [36]. After shedding, all infected snails were placed in $70 \%$ ethanol in collection jars for future molecular examination at the Natural History Museum (NHM), London.

\section{Identification and characterization of SWSs}

Public taps, wells and water pumps were considered as SWSs. In each shehia, SWSs were located with the help of the sheha, assistant sheha, or any village member familiar with the shehia and mapped with a handheld Garmin GPSMAP 62sc device (Garmin, Kansas City, USA). The availability of clean water was assessed by turning the tap, pumping the pump or checking for groundwater in wells and recorded. If water was not present when the SWS was visited, an inhabitant of a nearby house was questioned whether water was ever available from that point, when it was usually available and whether it was clean. Additional information on water availability was obtained by asking shehia inhabitants about the seasonality and day-to-day readiness of the water from each source.

\section{Distances}

Digital maps of the United Republic of Tanzania (including Zanzibar) were obtained from the International Livestock Research Institute (www.ilri.org) and shape files for Zanzibar were provided by the Health Management Information System of the Revolutionary Government of Zanzibar (www.hmis.zanhealth.go.tz). ArcGIS (version 10.2.2) (Esri, California, USA) was used to create maps displaying locations of villages, schools, HWCSs and SWSs in each investigated shehia. The World Geodic System 1984 (version WGS 84 revised in 2004) was used for mapping all coordinates. Coordinates were collected in degrees, minutes and seconds (DMS) and subsequently converted into decimal degrees (DD). The 'measure' tool on ArcGIS was used to determine distances between primary schools and the closest HWCSs or SWSs, respectively.

\section{Data management and analysis}

Field data were recorded on paper collection forms and subsequently entered into a Microsoft Excel 2013 (Version 14.0.0.0) database. All data were analysed using STATA/MP 14.1 (StataCorp, College Station, USA).
The S. haematobium prevalence was calculated from data collected during the parasitological surveys in 2012, 2013 and 2014. Treatment coverage was defined as the proportion of individuals among the total population that had received praziquantel tablets. With regard to the data obtained from the Ministry of Health, coverage was calculated as the percentage of people who had received tablets among the total number of people as recorded by the CDDs or teachers. In the post-treatment survey conducted in the SCORE schools and communities in early 2014, we calculated coverage as the proportion of pupils and adults, respectively, who received praziquantel among those who were interviewed and included into our analysis [33]. SWSs were classified as either 'always' available if water could be collected from the SWS throughout the year and at all times of the day, or 'not always' available if water could only be collected during certain seasons or times of the day. Univariable and multivariable regression analyses were used to investigate potential associations, expressed in odds ratios (ORs), between B. globosus presence or infected B. globosus presence as outcomes and water chemistry, ecological characteristics, water body types, presence of other snail species and behavioural activities as explanatory variables. Univariable regression was also used to explore an association between SWS type and water availability. Explanatory variables for the multivariable regression were all variables that were present in at least $5 \%$ of observations. Multivariable regression models were conducted for: (i) $B$. globosus presence and water chemistry; (ii) B. globosus presence and ecological characteristics; (iii) B. globosus presence and water body type; (iv) B. globosus presence and presence of other snails species; (v) B. globosus presence and human behavioural activities observed at HWCSs; (vi) infected B. globosus presence and water chemistry; and (vii) infected B. globosus presence and human behavioural activities observed at HWCSs. Multivariable regression models allowed for clustering and removed non-predicting covariates up to a significance level of 0.2 in a stepwise procedure.

\section{Results}

Selected persistent hot-spot and low-prevalence shehias As shown in Fig. 1, among the 45 shehias that are part of the SCORE project in Unguja, seven shehias fit the criteria for persistent hot-spots and 21 shehias fit the criteria for low-prevalence shehias. For operational feasibility, a total of five persistent hot-spot shehias and two low-prevalence shehias were included in the study. The following five persistent hot-spot shehias were selected: Bandamaji, Chaani, Kinyasini, Kitope and Koani. The following two shehias were selected as low-prevalence shehias: Dole and Mkwajuni. The location of each of the 


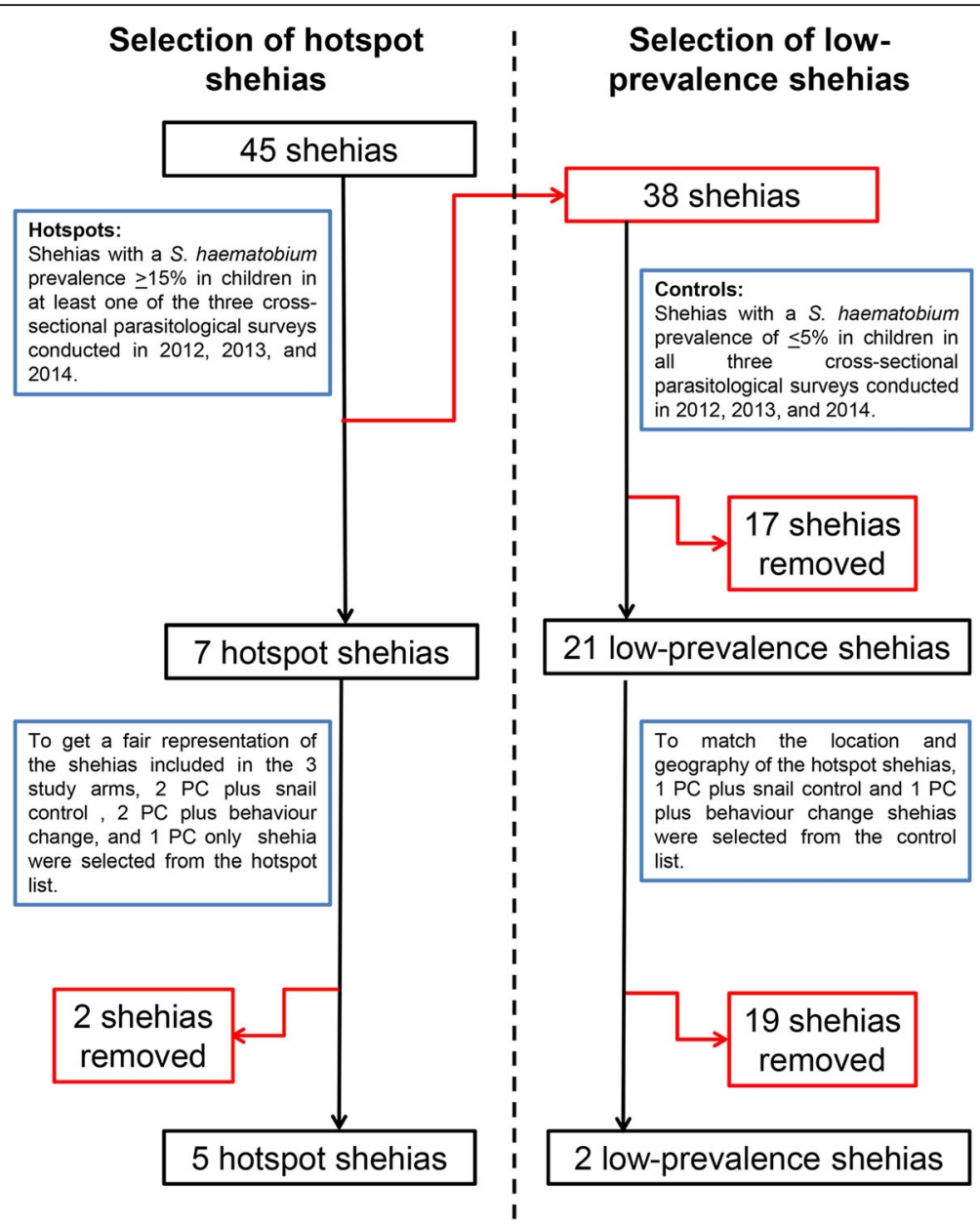

Fig. 1 Flowchart showing the inclusion procedure for persistent hot-spot and low-prevalence shehias in Unguja

surveyed shehias in Unguja is shown in Fig. 2, along with point locations of schools and HWCSs.

\section{Prevalence of S. haematobium in persistent hot-spot and low-prevalence shehias}

Table 1 shows the prevalence of S. haematobium in children visiting the primary schools located in any of the seven study shehias, stratified by survey year. The average S. haematobium prevalence across all three survey years in 9-12 years old schoolchildren was $20.0 \%$ (95\% CI: 18.1-22.0) in the five persistent hot-spot shehias and $0.78 \%$ (95 \% CI: 0.0-1.5) in the two low-prevalence shehias. Schoolchildren in Koani shehia had the highest average prevalence of $26.4 \%$ considering all surveys conducted in schools between 2012 and 2014 and also had the highest single-year prevalence of $37.6 \%$ in 2013.

\section{Treatment coverage in persistent hot-spot and low- prevalence shehias}

As indicated in Table 2, the coverage achieved in the four CWT rounds and the SBT round varied considerably per round and per shehia. While the coverage from rounds 1 and 2 conducted in 2012 was reported to be $\geq 75 \%$ in all persistent hot-spot shehias except Bandamaji, a $\geq 75 \%$ coverage in round 3 was only reported for Koani and in round 4 for Koani and Kinyasini. In the low-prevalence shehias, $\mathrm{a} \geq 75 \%$ coverage was reported for both Dole and Mkwajuni in rounds 1 and 2 and for Mkwajuni in round 4.

A SBT coverage was only reported by the Ministry of Health for the five persistent hot-spot shehias, but not for the two low-prevalence shehias. The school-based reported coverage was $\geq 75 \%$ in Chaani and Koani schools.

The SCORE coverage survey conducted for the CWT round 4 indicated an observed coverage of $\geq 75 \%$ only in the persistent hot-spot shehias Bandamaji and Chaani. Moreover, a coverage of $\geq 75 \%$ was observed in all schools in the five persistent hot-spot shehias and in the school in the low-prevalence shehia in Dole. Surveyed children in the school in the low-prevalence shehia Mkwajuni had not received treatment. 


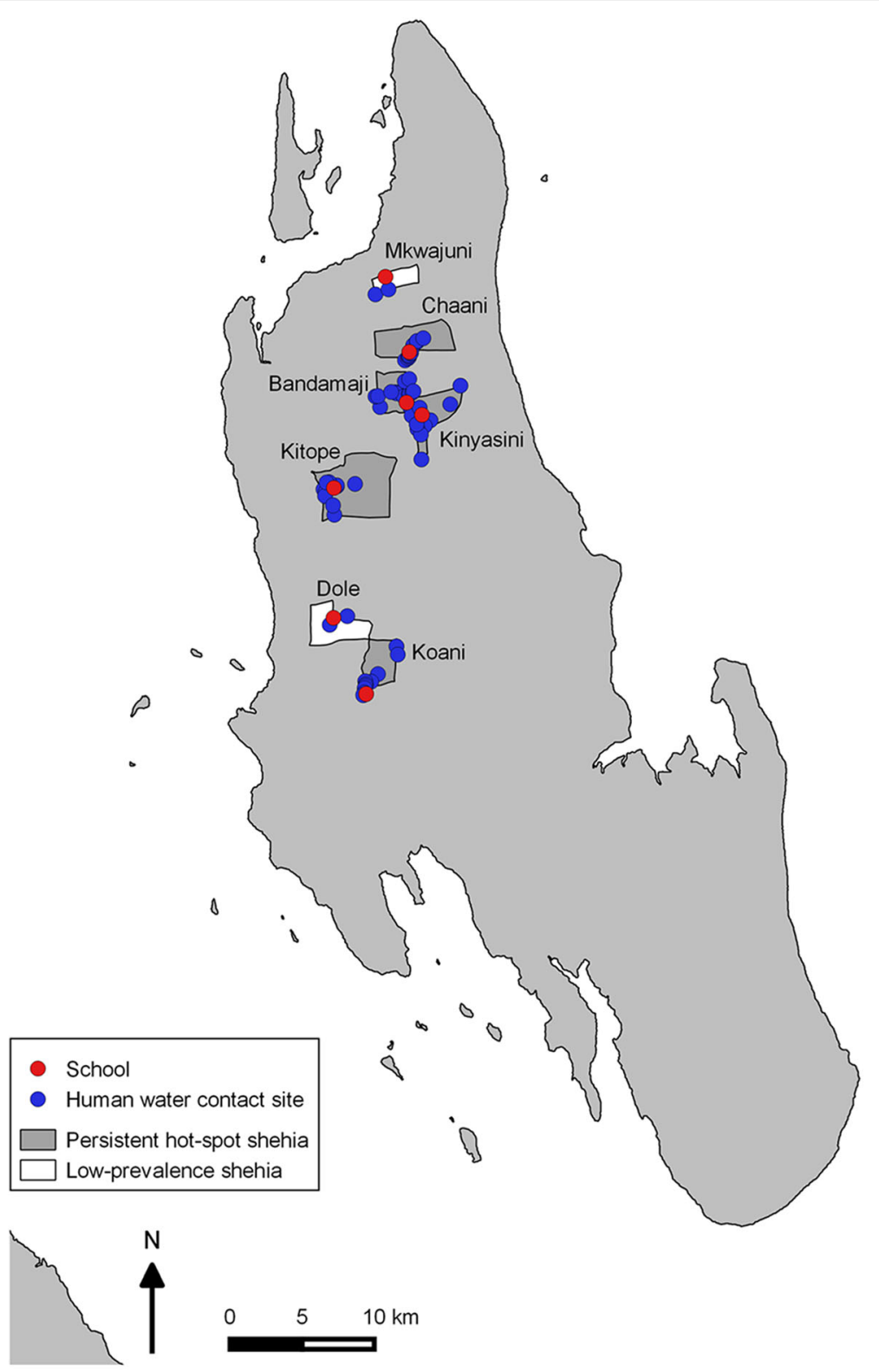

Fig. 2 Map of Unguja Island, Zanzibar, showing the location of selected persistent hot-spot and low-prevalence shehias

\section{Human-water contact sites in persistent hot-spot and low-prevalence shehias}

A total of 66 HWCS were surveyed across the five persistent hot-spot shehias and two low-prevalence shehias in Unguja. Among those, 56 were permanent and 10 were seasonal HWCS. As shown in Fig. 3, the number of HWCSs ranged from 10 to 15 in persistent hot-spot shehias, while only two HWCSs were located in each of the two low-prevalence shehias. Among the persistent hotspot shehias, Kinyasini had the highest number of HWCSs $(n=15)$, while Koani and Kitope had the lowest number $(n=10)$. Ponds were the most common freshwater bodies and every shehia, with the exception of
Chaani, had at least one HWCS at a pond. Rivers contained a lot of HWCSs in Kinyasini $(n=8)$ and Bandamaji $(n=3)$. Smaller streams included the majority of HWCSs in Chaani $(n=10)$ and Kitope $(n=7)$, but HWCSs at streams were also present in lower numbers in Kinyasini $(n=2)$ and Koani $(n=1)$. Rice paddies were only present in Koani $(n=1)$ and Chaani $(n=2)$. The four HWCSs in the low-prevalence shehias were one pond and one small stream in Mkwajuni and one pond and one rice paddy in Dole.

Water chemistry was recorded in 61 among the 66 HWCSs surveyed. The water chemistry device failed recording at two HWCSs at ponds in Bandamaji and at 
Table 1 Prevalence of S. haematobium in schoolchildren in persistent hot-spot and low-prevalence shehias in Unguja

\begin{tabular}{|c|c|c|c|c|c|c|c|c|c|}
\hline & \multirow{2}{*}{$\begin{array}{l}\text { Population } \\
\text { size }(2014)^{a}\end{array}$} & \multicolumn{2}{|c|}{2012 (1st year students) } & \multicolumn{2}{|c|}{2012 (9-12 year-old students) } & \multicolumn{2}{|c|}{2013 (9-12 year-old students) } & \multicolumn{2}{|c|}{2014 (9-12 year-old students) } \\
\hline & & $n / N^{b}$ & $\%^{c}$ & $n / N$ & $\%$ & $n / N$ & $\%$ & $n / N$ & $\%$ \\
\hline \multicolumn{10}{|c|}{ Persistent hot-spot shehias } \\
\hline Bandamaji & 1273 & $5 / 44$ & 11.4 & $16 / 94$ & 17.0 & $24 / 89$ & 27.0 & $32 / 117$ & 27.4 \\
\hline Kinyasni & 3302 & 24/100 & 24.0 & $21 / 105$ & 20.0 & 20/108 & 18.5 & $37 / 112$ & 33.0 \\
\hline Chaani & 3666 & $8 / 77$ & 10.4 & $6 / 131$ & 4.6 & $35 / 113$ & 31.0 & $12 / 119$ & 10.1 \\
\hline Koani & 3083 & $15 / 102$ & 14.7 & $15 / 94$ & 16.0 & $41 / 109$ & 37.6 & $27 / 111$ & 24.3 \\
\hline Kitope & 2526 & $24 / 96$ & 25.0 & $12 / 89$ & 13.5 & $9 / 111$ & 8.1 & $16 / 112$ & 14.3 \\
\hline \multicolumn{10}{|c|}{ Low-prevalence shehias } \\
\hline Dole & 3015 & $0 / 36$ & 0.0 & $0 / 49$ & 0.0 & $1 / 58$ & 1.7 & $0 / 62$ & 0.0 \\
\hline Mkwajuni & 4792 & $1 / 97$ & 1.0 & $0 / 118$ & 0.0 & $2 / 115$ & 1.7 & $1 / 111$ & 0.9 \\
\hline
\end{tabular}

${ }^{\text {a }}$ Shehia population sizes were estimated by multiplying the population size recorded in the 2012 Population and Housing census [29] by the annual growth rate $(2.8 \%)$

${ }^{\mathrm{b}} N=$ number of children sampled; $n=$ number of children infected

$c_{\%}=$ percentage of children infected with $S$. haematobium

three HWCSs at ponds in Koani. At the 61 HWCSs surveyed, the average temperature was $26.7{ }^{\circ} \mathrm{C}$ (range: $24.1-35.8{ }^{\circ} \mathrm{C}$ ), $\mathrm{pH}$ was 9.6 (range: $6.8-10.5$ ), conductivity was $482.1 \mu \mathrm{S}$ (range: 74.0-771.0 $\mu \mathrm{S}$ ) and total dissolved solids was $250.8 \mathrm{ppm}$ (range: 37.0-610.0 ppm). Salinity remained zero at all sites.

Intermediate host snail collections and cercariae shedding As shown in Fig. 3, B. globosus were found in at least half of all investigated HWCSs in all surveyed shehias, with the exception of Chaani, where the intermediate host snails were found in a third of all HWCSs. In total, 1111 B. globosus were collected from 39 HWCSs in persistent hot-spot shehias. Among the 1111 B. globosus, 26 (2.3 \%) were found to have a patent $S$. haematobium infection. As shown in
Fig. 4, the highest number of infected snails per shehia was found in Kinyasini, where 15 (8.2 \%) of B. globosus were infected. Among the four HWCSs in low-prevalence shehias, three contained B. globosus. However, none of the 205 B. globosus collected in the low-prevalence shehias shed cercariae. Univariable regression indicated no association between the presence of infected snails and the total number of $B$. globosus collected at each site $(\mathrm{OR}=1.0$, 95 \% CI: 1.0-1.0).

Bulinus forskalii was collected from a total of seven HWCSs in the persistent hot-spot shehias Bandamaji, Chaani, Kinyasini and Kitope, and from two HWCSs in the low-prevalence shehia Mkwajuni. No B. forskalii was found to be infected with $S$. haematobium. Two other groups of snails were also common and visually identified

Table 2 Treatment coverage in persistent hot-spot and low-prevalence shehias in Unguja

\begin{tabular}{|c|c|c|c|c|c|c|c|}
\hline & $\begin{array}{c}\text { CWT } 1 \text { in April } \\
2012\end{array}$ & $\begin{array}{c}\text { CWT } 2 \text { in November } \\
2012\end{array}$ & $\begin{array}{c}\text { CWT } 3 \text { in June } \\
2013\end{array}$ & $\begin{array}{c}\text { CWT } 4 \text { in November } \\
2013\end{array}$ & $\begin{array}{c}\text { SBT in November } \\
2013\end{array}$ & Post-CWT 4 & Post-SBT \\
\hline & $\begin{array}{l}\% \text { received } \\
\text { tablets }\end{array}$ & $\begin{array}{l}\% \text { received } \\
\text { tablets }\end{array}$ & $\begin{array}{l}\% \text { received } \\
\text { tablets }\end{array}$ & $\begin{array}{l}\% \text { received } \\
\text { tablets }\end{array}$ & $\begin{array}{l}\% \text { received } \\
\text { tablets }\end{array}$ & $\begin{array}{l}\text { \% received } \\
\text { tablets }\end{array}$ & $\begin{array}{l}\% \text { received } \\
\text { tablets }\end{array}$ \\
\hline \multicolumn{8}{|c|}{ Persistent hot-spot shehias } \\
\hline Bandamaji & 73.2 & 79.8 & 56.5 & 57.1 & 68.8 & 76.5 & 88.6 \\
\hline Kinyasini & 88.0 & 81.1 & 51.0 & 75.1 & 31.9 & 72.0 & 89.2 \\
\hline Chaani & 89.0 & 86.0 & 44.0 & 70.3 & 93.0 & 82.6 & 94.7 \\
\hline Koani & 78.3 & 93.1 & 78.3 & 77.0 & 77.8 & 72.0 & 86.7 \\
\hline Kitope & 94.5 & 92.5 & 72.7 & 70.5 & 52.6 & 46.0 & 84.2 \\
\hline Overall coverage & 87.8 & 86.7 & 58.2 & 71.7 & 65.6 & 69.6 & 88.8 \\
\hline \multicolumn{8}{|c|}{ Low-prevalence shehias } \\
\hline Dole & 90.3 & 87.3 & 74.9 & 65.3 & Not listed & 69.6 & 94.2 \\
\hline Mkwajuni & 94.0 & 78.9 & 58.9 & 79.1 & Not listed & 53.1 & 0.0 \\
\hline Overall coverage & 92.7 & 81.6 & 67.2 & 73.0 & & 61.1 & 34.4 \\
\hline
\end{tabular}

Abbreviations: CWT community-wide treatment, SBT school-based treatment 


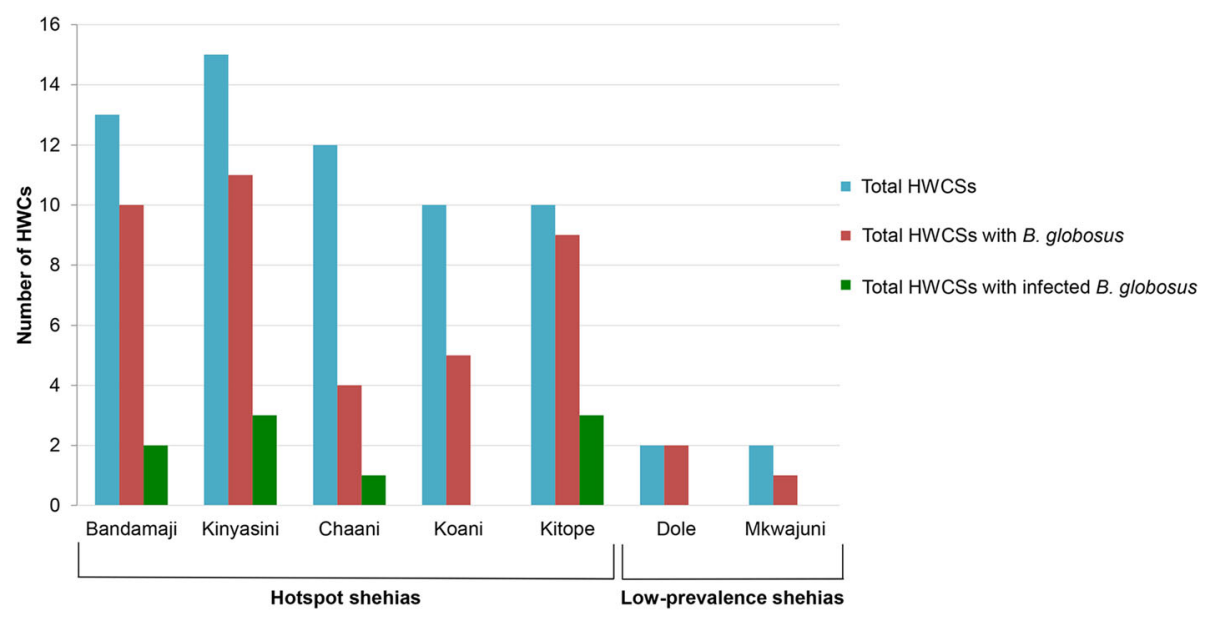

Fig. 3 Number of human-water contact sites in persistent hot-spot and low-prevalence shehias in Unguja

to the genus level: Pila sp. was found in $66.6 \%$ and Cleopatra sp. was found in $65.2 \%$ of the surveyed HWCSs.

\section{Factors influencing the presence of $B$. globosus and infected B. globosus}

Results of the univariable and multivariable regression models are provided in Additional file 1: Tables S1 and S2. Multivariable regression analyses showed that none of the investigated water chemistry or water body type characteristics were associated with the presence of $B$. globosus. With regard to ecological characteristics, only the presence of grass at HWCSs was significantly associated with the presence of B. globosus (OR $=4.2,95 \%$ CI: 1.2-14.6). The model for presence of other snail species revealed that the presence of Pila sp. was significantly associated with the presence of B. globosus ( $\mathrm{OR}=25.4$, 95 \% CI: 6.0-107.8).

The multivariable model including behavioural activities observed at HWCSs revealed an association of B. globosus presence with fishing $(\mathrm{OR}=49.4,95 \% \mathrm{CI}$ : 5.3-463.7), bathing ( $\mathrm{OR}=0.1,95 \% \mathrm{CI}: 0.0-0.6)$ and swimming/playing (OR = 0.0, $95 \% \mathrm{CI}: 0.0-0.1)$.
The presence of S. haematobium infected B. globosus was not significantly related to any water chemistry, ecological characteristics, water body types or presence of other snail species. However, a significant association between the presence of infected B. globosus and the following behavioural activities was determined in a multivariable model including behavioural parameters: washing dishes ( $\mathrm{OR}=98.9,95 \% \mathrm{CI}$ : 5.2-1881.4), fishing $(\mathrm{OR}=58.3$, 95 \% CI: 1.3-2616.6), water collection for drinking and cooking $(\mathrm{OR}=0.0,95 \% \mathrm{CI}$ : $0.0-0.2)$, and clothes washing (OR $=0.2$, $95 \% \mathrm{CI}$ : 0.0-0.9).

\section{Characteristics of safe water sources}

Table 3 indicates that in persistent hot-spot shehias, the total number of public SWSs per shehia ranged from 16 to 61 and included wells, pumps and taps. Taps were the most common SWSs in Kitope $(75.9 \%)$ and Chaani (63.9 \%). Wells were more abundant in Bandamaji (93.8 \%), Koani (80.7 \%) and Kinyasini (80.6 \%). The number of pumps was generally low. Only in Chaani, pumps made up for $13.1 \%$ among other SWS. Noteworthy, $90.3 \%, 84.2 \%, 56.3 \%, 54.1 \%$ and $20.7 \%$ of the

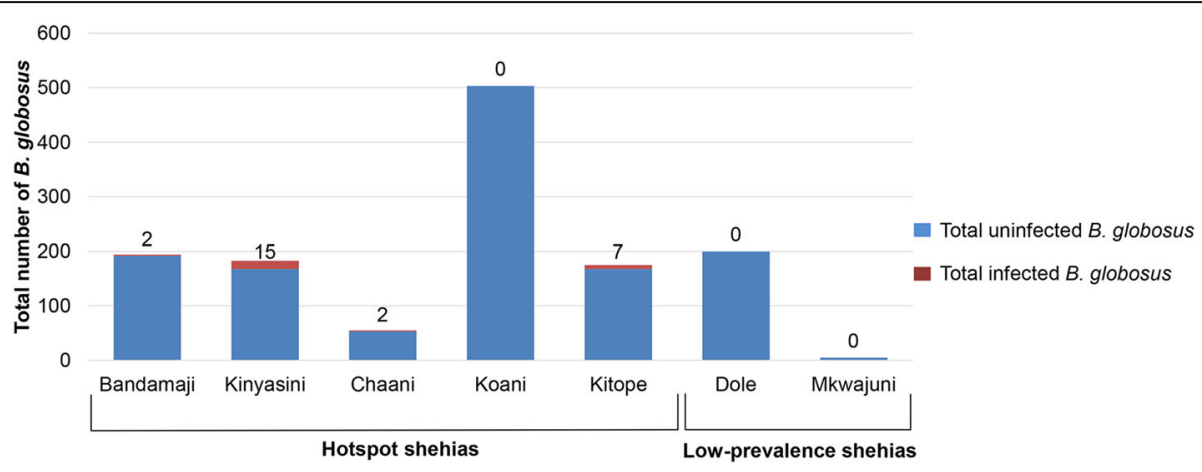

Fig. 4 Number of B. globosus and B. globosus shedding S. haematobium cercariae per shehia in Unguja 
Table 3 Abundance of public safe water sources supplying persistent hot-spot and low-prevalence shehias in Unguja

\begin{tabular}{|c|c|c|c|c|c|c|c|c|c|c|}
\hline & \multicolumn{2}{|l|}{ Wells } & \multicolumn{2}{|l|}{ Taps } & \multicolumn{2}{|c|}{ Pumps } & \multicolumn{2}{|c|}{ Other SWSs ${ }^{c}$} & \multicolumn{2}{|c|}{ Total SWSs } \\
\hline & $n / N^{a}$ & $\%^{\mathrm{b}}$ & $n / N$ & $\%$ & $n / N$ & $\%$ & $n / N$ & $\%$ & $n / N$ & $\%$ \\
\hline \multicolumn{11}{|c|}{ Persistent hot-spot shehias } \\
\hline Bandamaji & $8 / 15$ & 53.3 & $0 / 0$ & - & $1 / 1$ & 100 & $0 / 0$ & - & $9 / 16$ & 56.3 \\
\hline Kinyasini & $22 / 25$ & 88.0 & $3 / 3$ & 100 & $3 / 3$ & 100 & 0/0 & - & $28 / 31$ & 90.3 \\
\hline Chaani & $3 / 14$ & 21.4 & $23 / 39$ & 59.0 & $7 / 8$ & 87.5 & $0 / 0$ & - & $33 / 61$ & 54.1 \\
\hline Koani & $40 / 46$ & 87.0 & $7 / 10$ & 70.0 & $1 / 1$ & 100 & $0 / 0$ & - & $48 / 57$ & 84.2 \\
\hline Kitope & $10 / 13$ & 76.9 & $2 / 44$ & 4.6 & $0 / 1$ & 0.00 & 0/0 & - & $14 / 58$ & 24.1 \\
\hline \multicolumn{11}{|c|}{ Low-prevalence shehias } \\
\hline Dole & $6 / 12$ & 50.0 & 10/39 & 25.6 & $1 / 1$ & 100 & $1 / 2$ & 50.0 & $18 / 54$ & 33.3 \\
\hline Mkwajuni & $2 / 2$ & 100.0 & $18 / 20$ & 90.0 & 0/0 & - & 0/0 & - & $20 / 22$ & 90.9 \\
\hline
\end{tabular}

Abbreviations: SWS safe water source

${ }^{a} N=$ total number of public safe water sources; $n=$ number of SWSs that constantly provided water

$\mathrm{b}_{\%}=$ percentage of SWSs that constantly provided water

'Other SWSs included a hose and a leaking electric ground water pump in Dole

SWSs in Kinyasini, Koani, Bandamaji, Chaani and Kitope, respectively, had water constantly available.

In low-prevalence shehias, the total number of public SWSs per shehia ranged from 22 to 54 and included wells, pumps and taps and in Dole also a hose and a leaking electric groundwater pump. Taps were the most common SWS in both Mkwajuni (90.9 \%) and Dole (72.2\%). In the low-prevalence shehias, water was constantly available in $90.9 \%$ of the SWSs in Mkwajuni and in $33.3 \%$ of the SWSs in Dole.

The mean number of SWSs was 44.6 (95 \% CI: 27.062.2) and 38.0 (95 \% CI: 6.6-69.4) in persistent hot-spot and low-prevalence shehias, respectively. Water was constantly available in $61.6 \%$ (95 \% CI: 38.4-84.8) of the SWSs in persistent hot-spot shehias and in 62.0 \% (95\% CI: $5.2-$ 118.8) of the SWSs in low-prevalence shehias.

Univariable regression showed that taps had significantly lower odds of water being constantly available in persistent hot-spot shehias $(\mathrm{OR}=0.2,95 \% \mathrm{CI}$ : 0.1-0.4), but not in low-prevalence shehias $(\mathrm{OR}=0.7,95 \% \mathrm{CI}$ : $0.2-2.2$ ). No other SWS type was significantly related to water availability.

\section{Distances from schools to human-water contact sites and safe water sources}

Table 4 indicates the direct (i.e. straight line) distances from the primary school in each shehia to the nearest HWCS or SWS. In persistent hot-spot shehias, the average distance from primary schools to the nearest HWCS was $229 \mathrm{~m}$ (95\% CI: 58-400) and to the nearest HWCS containing B. globosus was 245 m (95\% CI: 90-400). In low-prevalence shehias, the average distance to both the nearest HWCS and the nearest HWCS with B. globosus was 722 m (95 \% CI: -1506-2950).

The average distance from primary schools to the nearest SWS was 142 m (95 \% CI: -28-312) in persistent hot-spot shehias and 134 m (95 \% CI: -799-1067) in low-prevalence shehias. The direct way to the nearest SWS with constant water availability was 183 m (95\% CI: 22-344) in persistent hot-spot shehias and 210 m (95\% CI: 179-241) in lowprevalence shehias.

In all shehias but Koani, the distance from the primary school to the nearest SWS and SWS with constant water flow was shorter than the distance to the nearest HWCS. In Koani, the distance from Mwera primary school to the nearest HWCS was $152 \mathrm{~m}$, while the distance to the nearest SWS was $376 \mathrm{~m}$.

\section{Discussion}

Urogenital schistosomiasis transmission hot-spot areas in Zanzibar have remained resilient to PC and additional control interventions for multiple years. We aimed to better characterise persistent hot-spot shehias in Unguja to inform and improve intervention planning for schistosomiasis elimination in Zanzibar.

No major difference in the treatment coverage was found between persistent hot-spot and low-prevalence shehias. The SCORE coverage survey revealed that while the observed coverage in all targeted schools in 2013 was above the $75 \%$ mark, the overall observed coverage for CWT in persistent hot-spot and low-prevalence shehias was $70 \%$ and $61 \%$, respectively. Hence, a substantial part of the population remained untreated and potentially infected individuals might have contributed to the perpetuation of transmission in areas where intermediate host snails were present. Recent modelling work has shown that interruption of schistosomiasis transmission in moderate intensity settings is possible, if at least $75 \%$ of school-aged children are treated annually with praziquantel and if a moderate treatment coverage in adults is reached [37]. However, heterogeneity in terms of water contact type and the sort of aquatic habitat near 
Table 4 Distances (in metres) from schools to human-water contact sites and safe water sources

\begin{tabular}{|c|c|c|c|c|c|}
\hline Primary school & HWCS & $\begin{array}{l}\text { HWCS with } \\
\text { B. globosus }\end{array}$ & $\begin{array}{l}\text { HWCS with } \\
\text { infected B. globosus }\end{array}$ & SWS & $\begin{array}{l}\text { SWS always } \\
\text { available }\end{array}$ \\
\hline \multicolumn{6}{|c|}{ Persistent hot-spot shehias } \\
\hline Bandamaji & 460 & 460 & 620 & 95 & 95 \\
\hline Kinyasini & 169 & 169 & 568 & 143 & 143 \\
\hline Chaani Masingini & 134 & 148 & 148 & 54 & 54 \\
\hline Koani & 152 & 218 & - & 376 & 376 \\
\hline Kitope & 229 & 229 & 531 & 44 & 246 \\
\hline \multicolumn{6}{|c|}{ Low-prevalence shehias } \\
\hline Dole & 546 & 546 & - & 60 & 212 \\
\hline Mkwajuni & 897 & 897 & - & 207 & 207 \\
\hline
\end{tabular}

Abbreviations: HWCS nearest human-water contact site at freshwater bodies, SWS nearest safe water source

each village had not been considered and would require individual based stochastic models, which incorporate spatial transmission [37, 38].

Indeed, we identified considerably more HWCSs containing B. globosus (average: $n=8 v s n=2$ ) and B. globosus infected with S. haematobium (average: $n=2$ vs $n=0$ ) in persistent hot-spot than in low-prevalence shehias. Bulinus globosus infected with S. haematobium were found exclusively at HWCSs located in hot-spot but not in low-prevalence shehias. The proportion of snails with a patent infection (2\%) found in the persistent hot-spot shehias in our study, is in line with the proportion of snails collected with patent infections reported from other studies conducted in Zanzibar and elsewhere in subSaharan Africa [35, 39-41]. While these infection levels seem rather low considering the S. haematobium prevalence in children in the persistent hot-spot shehias, previous work conducted in Zanzibar has shown that the cercariae shedding method misses many prepatent infections [35]. If more advanced, molecular techniques are used for screening snails instead, it is likely to detect a considerably higher number of infected snails [35, 40, 42-44]. Rapid detection of schistosome cercariae ribosomal DNA in environmental samples using new methods could also aid in uncovering transmission sites that may have previously been missed following classic snail 'shedding' methods [45].

Our study also revealed that the distance to HWCSs containing intermediate host snails was shorter from schools with high $S$. haematobium prevalence than from the low-prevalence schools where the $S$. haematobium prevalence was $<5 \%$. Similarly, another study from Zanzibar had shown that the highest $S$. haematobium prevalence was found in village hamlets that were located in close proximity to HWCSs containing B. globosus and infected B. globosus [17]. Also in Mali, the vicinity of intermediate host snail breeding sites in six communities was one of the main risk factors for S. haematobium infection in residents [46].
The presence of B. globosus in our study areas was associated with certain behavioural activities observed at the HWCSs. Bathing and swimming/ playing significantly reduced the odds of finding B. globosus at HWCSs. This observation might be explained by the use of soap and the turbulent nature of these activities creating an environment less favourable for B. globosus [34]. In contrast, washing dishes and fishing significantly increased the odds of finding B. globosus at HWCS, perhaps indicating a nutrient rich environment caused by food remnants washed from dishes and indicated by the presence of fish, respectively. Interestingly, intermediate host snails infected with S. haematobium were significantly less likely to be present at HWCSs where water was collected for drinking and cooking. People not urinating and contaminating the water source that is used for potable water collection might be an explanation for this observation. Infected snails were also less present at HWCSs used for washing clothes. Soap might have an adverse effect on cercariae, as suggested elsewhere $[17,47]$.

In line with the baseline snail survey conducted at the onset of the SCORE operational research trial [14], but in contrast to studies previously conducted in Unguja $[32,35]$, water characteristics were not linked to the presence/ absence of B. globosus in the present study. Other, not presently measured factors and environmental dynamics, such as the permanence of the water body itself or flooding events that re-seed areas, might better predict the occurrence of intermediate host snails and merit future investigation.

We found that on average there were less taps in persistent hot-spot shehias than in low-prevalence shehias ( $n=19$ vs $n=30$ ). In addition, the taps located in persistent hot-spot shehias had significantly lower odds of providing a constantly available water supply. While wells constituted a frequent and relatively constant water source particularly in the persistent hot-spot shehias of our study, they are reasonably cumbersome to use for children, who might use nearby freshwater bodies as 
alternatives for bathing or washing. The lack of reliable taps from which water collection is easy might contribute to people using potentially infectious freshwater bodies as a simple alternative for conducting domestic chores [48]. Improving and increasing the access to safe water and additional water, sanitation and hygiene (WASH) measures should be part of a sustainable schistosomiasis elimination strategy in Zanzibar and elsewhere [49-53].

Interestingly, in the "hottest" persistent hot-spot shehia, Koani, the distance from the school to the nearest HWCS $(152 \mathrm{~m})$ and HWCS containing B. globosus $(218 \mathrm{~m})$ was much shorter than the distance to the nearest SWS $(376 \mathrm{~m})$, although it was the shehia with the highest number of reliably working SWSs. Moreover, the highest number of B. globosus $(n=503)$ was collected in Koani.

Our small study design clearly limits the ability to attribute a meaning to unexpected findings. However, already the inclusion of only a small number of shehias has provided evidence that characteristics such as a larger number of HWCSs containing intermediate host snails and B. globosus infected with S. haematobium, a shorter distance from the primary school to the nearest HWCS and the lack of easy to use and reliably functioning SWSs play an important role in defining persistent hot-spot areas. This information can help to define, tailor and target future multidisciplinary interventions that will effectively reduce urogenital schistosomiasis transmission hot-spots in Zanzibar.

Recent reviews and analyses of the existing literature have outlined snail control as the most effective way of reducing schistosomiasis prevalence in endemic areas $[54,55]$. Indeed, to sustainably curtail schistosomiasis transmission in Zanzibar, large-scale mollusciciding in hot-spot areas and focussed to HWCSs will be essential. With regard to the movement of potentially infected individuals between the shehias and the potential for recontamination of treated freshwater bodies, it will be important to identify all HWCSs and the intermediate host snail abundance in areas of high transmission and to rigorously treat HWCSs regularly when intermediate host snails are present. The molluscicide niclosamide is the only commercially available and approved chemical for control of freshwater snails. However, while it is effective, it does have an impact on other aquatic organisms such as fish and amphibia and should be used carefully.

In addition to $\mathrm{PC}$ and area-wide snail control, the reduction of human-water contact by improving access to easy to use and reliably working SWSs and the minimisation of water contamination by changing human behaviour in hot-spot areas will be crucial for reaching elimination of transmission. Partnering with organisations and ministries that have the infrastructure and expertise to support and enhance WASH and educational measures can strengthen future interventions for elimination of urogenital schistosomiasis transmission in Zanzibar and elsewhere.

\section{Conclusion}

The investigated persistent hot-spots in Zanzibar were characterized by a larger number of human-water contact sites containing intermediate host snails and B. globosus infected with S. haematobium, a shorter distance from the primary school to the nearest human-water contact site and the lack of easy to use and reliably functioning safe water sources. Rigorous focal mollusciciding or alternative snail control measures at all human-water contact sites near schools and villages, increasing access to safe water and sanitation, and enhanced behaviour change and health communication measures are needed to reduce prevalences in persistent hot-spot areas in order to reach elimination of schistosomiasis transmission.

\section{Additional file}

Additional file 1: Results of univariable and multivariable analyses. (XLS $49 \mathrm{~kb})$

\begin{abstract}
Abbreviations
CDD: Community drug distributor; Cl: Confidence interval; CWT: Communitywide treatment; HWCS: Human-water contact site; OR: Odds ratio; PC: Preventative chemotherapy; SCAN: Schistosomiasis Collection at the Natural History Museum; SCORE: Schistosomiasis Consortium for Operational Research and Evaluation; SWS: Safe water source; WASH: Water, sanitation and hygiene; WHO: World Health Organization; ZEST: Zanzibar Elimination of Schistosomiasis Transmission;
\end{abstract}

\section{Acknowledgements}

We are grateful to all the staff of the Zanzibar Neglected Tropical Diseases Programme who helped to generate data used in this study. The Zanzibar Neglected Tropical Disease Programme acknowledges the World Health

Organization for the donation of praziquantel to cover biannual preventative chemotherapy of the population and the Schistosomiasis Control Initiative

for covering the treatment implementation costs. Thanks also to the Schistosomiasis Consortium for Operational Research and Evaluation secretariat for their great support for these operational research projects.

\section{Funding}

This study received financial support from the University of Georgia Research Foundation Inc., which is funded by the Bill \& Melinda Gates Foundation for these Schistosomiasis Consortium for Operational Research and Evaluation (SCORE) projects (prime award no. 50816, sub-award no. RR374-053/ 4893206). SK is financially supported by sub-award no. RR374-053/4893196. TP received financial support from the London School for Hygiene and Tropical Medicine for his MSc project. The funders had no role in study design, data collection and analysis, interpretation of the data, or writing the manuscript.

\section{Availability of data and material}

Most of the data generated or analysed during this study are included in this article and its Additional file. The datasets generated during and/or analysed during the current study that are not included in this published article are part of a multi-year research study that is not yet concluded and published. These datasets might be available from the corresponding author on reasonable request. 


\section{Authors' contributions}

Conception and design of the study: TP, BP, JM, KAM, FK, DR, SK. Acquisition of data: TP, MAM, ANK, ISK. Analysis and interpretation of data: TP, SK; Drafting the article: TP, SK. Revising the article critically for important intellectual content: TP, BP, JM, ISK, KAM, FK, DR, SK. All authors read and approved the final manuscript.

\section{Competing interests}

The authors declare that they have no competing interests.

\section{Consent for publication}

Not applicable.

\section{Ethics approval and consent to participate}

This study was embedded in activities of the SCORE operational research project, which has received ethical approval from the Zanzibar Medical Research Ethics Committee in Stonetown, Zanzibar (ZAMREC, reference no. ZAMREC 0003/Sept/011), the "Ethikkommission beider Basel" (EKBB) in Basel, Switzerland (reference no. 236/11) and the Institutional Review Board of the University of Georgia in Athens, United States of America (project no. 201210138-0). Additionally, ethical approval for the study protocol "Identification and characterisation of transmission hot-spots for urogenital schistosomiasis in Zanzibar, United Republic of Tanzania" was granted by the London School of Hygiene and Tropical Medicine MSc Ethics committee (LSHTM MSc Ethics reference no. 7566).

All participants of the SCORE study, and in the case of children their parents, provided written informed consent [14]. District authorities and shehas were informed by letter about the purpose and procedures of the research on persistent S. haematobium transmission hot-spot and low-prevalence shehias. In a follow-up phone call to the sheha, further details were discussed and a suitable date for the study team to visit the shehia was arranged. Final oral approval for the fieldwork within the respective community in the frame of the project was gained when meeting the sheha on the day of the survey.

\section{Author details}

'Wolfson Wellcome Biomedical Laboratories, Department of Life Sciences, Natural History Museum, Cromwell Road, London SW7 5BD, UK. ${ }^{2}$ Department of Pathology and Pathogen Biology, Centre for Emerging, Endemic and Exotic Diseases, Royal Veterinary College, University of London, Hawkshead Lane, Hatfield, Hertfordshire AL9 7TA, UK. Independent Consultant, Schistosomiasis Consortium for Operational Research and Evaluation, University of Georgia, Athens, GA, USA. ${ }^{4}$ Zanzibar Neglected Tropical Diseases Programme, Ministry of Health, P.O. Box 236, Zanzibar Town, Unguja, United Republic of Tanzania. ${ }^{5}$ Swiss Tropical and Public Health Institute, Socinstrasse 57, P.O. BoxCH-4002 Basel, Switzerland. ${ }^{6}$ University of Basel, Petersplatz 1, CH-4003 Basel, Switzerland.

\section{Received: 15 August 2016 Accepted: 12 October 2016}

\section{Published online: 16 December 2016}

\section{References}

1. Aregawi MW, Ali AS, Al-Mafazy A-W, Molteni F, Katikiti S, Warsame M, et al. Reductions in malaria and anaemia case and death burden at hospitals following scale-up of malaria control in Zanzibar, 1999-2008. Malar J. 2011; 10(1):46.

2. Bhattarai A, Ali AS, Kachur SP, Martensson A, Abbas AK, Khatib R, et al. Impact of artemisinin-based combination therapy and insecticide-treated nets on malaria burden in Zanzibar. PLoS Med. 2007;4(11):e309.

3. Vreysen M, Saleh K, Ali M, Abdulla A, Zhu Z, Juma K, et al. The use of the sterile insect technique (SIT) for the eradication of the tsetse fly Glossina austeni (Diptera: Glossinidae) on the Island of Unguja (Zanzibar). J Econ Entomol. 2000;93:123-35.

4. Mohammed KA, Molyneux DH, Albonico M, Rio F. Progress towards eliminating lymphatic filariasis in Zanzibar: a model programme. Trends Parasitol. 2006;22(7):340-4.

5. Rebollo MP, Mohammed KA, Thomas B, Ame S, Ali SM, Cano J, et al. Cessation of mass drug administration for lymphatic filariasis in Zanzibar in 2006: was transmission interrupted? PLoS Negl Trop Dis. 2015;9(3):e3669.

6. Forsyth D, MacDonald G. Urological complications of endemic schistosomiasis in schoolchildren Part 2. Donge school, Zanzibar. Trans R Soc Trop Med Hyg. 1966;60(5):568-78.
7. Savioli L, Dixon H, Kisumku UM, Mott KE. Control of morbidity due to Schistosoma haematobium on Pemba island; selective population chemotherapy of schoolchildren with haematuria to identify high-risk localities. Trans R Soc Trop Med Hyg. 1989;83(6):805-10.

8. Savioli L, Mott K. Urinary schistosomiasis on Pemba Island: low-cost diagnosis for control in a primary health care setting. Parasitol Today. 1989; 5(10):333-7

9. Lwambo N, Savioli L, Kisumku U, Alawi K, Bundy D. The relationship between prevalence of Schistosoma haematobium infection and different morbidity indicators during the course of a control programme on Pemba Island. Trans R Soc Trop Med Hyg. 1997;91(6):643-6.

10. Stothard JR, Mgeni A, Khamis S, Seto E, Ramsan M, Rollinson D. Urinary schistosomiasis in schoolchildren on Zanzibar Island (Unguja), Tanzania: a parasitological survey supplemented with questionnaires. Trans R Soc Trop Med Hyg. 2002;96(5):507-14

11. Stothard JR, French MD, Khamis IS, Basáñez M-G, Rollinson D. The epidemiology and control of urinary schistosomiasis and soil-transmitted helminthiasis in schoolchildren on Unguja Island, Zanzibar. Trans R Soc Trop Med Hyg. 2009;103(10):1031-44.

12. Knopp S, Stothard JR, Rollinson D, Mohammed KA, Khamis I, Marti H, et al. From morbidity control to transmission control: time to change tactics against helminths on Unguja Island, Zanzibar. Acta Trop. 2011;128(2):412-22.

13. Knopp S, Mohammed KA, Ali SM, Khamis IS, Ame SM, Albonico M, et al. Study and implementation of urogenital schistosomiasis elimination in Zanzibar (Unguja and Pemba islands) using an integrated multidisciplinary approach. BMC Public Health. 2012;12(1):930.

14. Knopp S, Person B, Ame SM, Mohammed KA, Ali SM, Khamis IS, et al. Elimination of schistosomiasis transmission in Zanzibar: baseline findings before the onset of a randomized intervention trial. PLoS Negl Trop Dis. 2013;7(10):e2474.

15. WHO. Schistosomiasis: progress report 2001-2011, strategic plan 2012-2020. Geneva: World Health Organization; 2013. Accessed 14 Jun 2016.

16. $\mathrm{WHO}$. Accelerating work to overcome the global impact of neglected tropical diseases: a roadmap for implementation: executive summary. Geneva: World Health Organization; 2012. Accessed 14 Jun 2016.

17. Rudge JW, Stothard JR, Basáñez M-G, Mgeni AF, Khamis IS, Khamis AN, et al. Micro-epidemiology of urinary schistosomiasis in Zanzibar: local risk factors associated with distribution of infections among schoolchildren and relevance for control. Acta Trop. 2008;105(1):45-54.

18. Guidi A, Andolina C, Makame Ame S, Albonico M, Cioli D, Juma Haji H. Praziquantel efficacy and long-term appraisal of schistosomiasis control in Pemba Island. Trop Med Int Health. 2010;15(5):614-8.

19. Laamrani H, Mahjour J, Madsen H, Khallaayoune K, Gryseels B. Schistosoma haematobium in Morocco: moving from control to elimination. Parasitol Today. 2000;16(6):257-60.

20. Clennon JA, King CH, Muchiri EM, Kariuki HC, Ouma JH, Mungai P, et al. Spatial patterns of urinary schistosomiasis infection in a highly endemic area of coastal Kenya. Am J Trop Med Hyg. 2004;70(4):443-8.

21. Clennon JA, Mungai PL, Muchiri EM, King CH, Kitron U. Spatial and temporal variations in local transmission of Schistosoma haematobium in Msambweni, Kenya. Am J Trop Med Hyg. 2006;75(6):1034-41.

22. Sang HC, Muchiri G, Ombok M, Odiere MR, Mwinzi P. Schistosoma haematobium hotspots in south Nyanza, western Kenya: prevalence, distribution and co-endemicity with Schistosoma mansoni and soiltransmitted helminths. Parasit Vectors. 2014;7:125.

23. Zou L, Ruan S. Schistosomiasis transmission and control in China. Acta Trop. 2015;143:51-7.

24. Steinmann P, Keiser J, Bos R, Tanner M, Utzinger J. Schistosomiasis and water resources development: systematic review, meta-analysis, and estimates of people at risk. Lancet Infect Dis. 2006;6(7):411-25.

25. Sousa-Figueiredo JC, Stanton MC, Katokele S, Arinaitwe M, Adriko M, Balfour $L$, et al. Mapping of schistosomiasis and soil-transmitted helminths in Namibia: the first large-scale protocol to formally include rapid diagnostic tests. PLoS Negl Trop Dis. 2015;9(7):e0003831.

26. Chitsulo L, Engels D, Montresor A, Savioli L. The global status of schistosomiasis and its control. Acta Trop. 2000;77(1):41-51.

27. King $\mathrm{CH}$. Toward the elimination of schistosomiasis. N Engl J Med. 2009; 360(2):106-9.

28. Rollinson D, Knopp S, Levitz S, Stothard JR, Tchuem Tchuenté LA, Garba A, et al. Time to set the agenda for schistosomiasis elimination. Acta Trop. 2013;128(2):423-40. 
29. Office of Chief Government Statistician Presidents Office. 2012 Population and Housing Census; Population Distribution by Administrative Areas. Economy and Development Planning Zanzibar. 2013.

30. Stothard JR, Mgeni A, Alawi K, Savioli I, Rollinson D. Observations on shell morphology, enzymes and random amplified polymorphic DNA (RAPD) in Bulinus africanus group snails (Gastropoda: Planorbidae) in Zanzibar. J Molluscan Stud. 1997;63(4):489-503.

31. Stothard JR, Loxton N, Rollinson D, Mgeni A, Khamis S, Ameri H, et al. The transmission status of Bulinus on Zanzibar Island (Unguja), with implications for control of urinary schistosomiasis. Ann Trop Med Parasitol. 2000;94(1):87-94.

32. Stothard JR, Mgeni A, Khamis S, Seto E, Ramsan M, Hubbard S, et al. New insights into the transmission biology of urinary schistosomiasis in Zanzibar. Trans R Soc Trop Med Hyg. 2002;96(5):470-5.

33. Knopp S, Person B, Ame SM, Ali SM, Muhsin J, Juma S, et al. Praziquantel coverage in schools and communities targeted for the elimination of urogenital schistosomiasis in Zanzibar: a cross-sectional survey. Parasit Vectors. 2016;9(1):1.

34. Brown DS. Freshwater snails of Africa and their medical importance. 2nd ed. London: Taylor \& Francis; 1994.

35. Allan FE, Dunn AM, Emery AM, Stothard JR, Johnston DA, Kane RA, et al. Use of sentinel snails for the detection of Schistosoma haematobium transmission on Zanzibar and observations on transmission patterns. Acta Trop. 2013;128(2):234-40.

36. Emery AM, Allan FE, Rabone ME, Rollinson D. Schistosomiasis collection at NHM (SCAN). Parasit Vectors. 2012;5:185.

37. Anderson R, Turner H, Farrell S, Yang J, Truscott J. What is required in terms of mass drug administration to interrupt the transmission of schistosome parasites in regions of endemic infection? Parasit Vectors. 2015;8(1):1.

38. Fulford A, Butterworth A, Ouma J, Sturrock R. A statistical approach to schistosome population dynamics and estimation of the life-span of Schistosoma mansoni in man. Parasitology. 1995;110(03):307-16.

39. Anderson R, May R. Prevalence of schistosome infections within molluscan populations: observed patterns and theoretical predictions. Parasitology. 1979;79(01):63-94.

40. Hamburger J, Hoffman O, Kariuki HC, Muchiri EM, Ouma JH, Koech DK, et al. Large-scale, polymerase chain reaction-based surveillance of Schistosoma haematobium DNA in snails from transmission sites in coastal Kenya: a new tool for studying the dynamics of snail infection. Am J Trop Med Hyg. 2004; 71(6):765-73.

41. Senghor B, Diaw OT, Doucoure S, Seye M, Talla I, Diallo A, et al. Study of the snail intermediate hosts of urogenital schistosomiasis in Niakhar, region of Fatick, West central Senegal. Parasit Vectors. 2015;8(1):1.

42. Abbasi I, King CH, Muchiri EM, Hamburger J. Detection of Schistosoma mansoni and Schistosoma haematobium DNA by loop-mediated isothermal amplification: identification of infected snails from early prepatency. Am J Trop Med Hyg. 2010;83(2):427.

43. Hamburger J, Ramzy R, Jourdane J, Ruppel A. A polymerase chain reaction assay for detecting snails infected with bilharzia parasites (Schistosoma mansoni) from very early prepatency. Am J Trop Med Hyg. 1998;59(6):872-6.

44. Hamburger J, Abbasi I, Kariuki C, Wanjala A, Mzungu E, Mungai P, et al. Evaluation of loop-mediated isothermal amplification suitable for molecular monitoring of schistosome-infected snails in field laboratories. Am J Trop Med Hyg. 2013;88(2):344-51.

45. Jothikumar N, Mull BJ, Brant SV, Loker ES, Collinson J, Secor WE, et al. Realtime PCR and sequencing assays for rapid detection and identification of avian schistosomes in environmental samples. Appl Environ Microbiol. 2015; 81(12):4207-15.

46. Dabo A, Diarra AZ, Machault V, Touré O, Niambélé DS, Kanté A, et al. Urban schistosomiasis and associated determinant factors among school children in Bamako, Mali, West Africa. Infect Dis Poverty. 2015;4(1):1-13.

47. Okwuosa VN, Osuala FO. Toxicity of washing soaps to Schistosoma mansoni cercariae and effects of sublethal concentrations on infectivity in mice. Appl Parasitol. 1993;34(1):69-75.

48. UNICEF. Soap, toilets and taps. 2009. http://www.unicef.org/wash/files/ FINAL_Soap_Toilets_Taps.pdf. Accessed 13 July 2016.

49. Freeman MC, Ogden S, Jacobson J, Abbott D, Addiss DG, Amnie AG, et al. Integration of water, sanitation, and hygiene for the prevention and control of neglected tropical diseases: a rationale for inter-sectoral collaboration. PLoS Negl Trop Dis. 2013;7(9):e2439.

50. Campbell SJ, Savage GB, Gray DJ, Atkinson J-AM, Magalhaes RJS, Nery SV, et al. Water, sanitation, and hygiene (WASH): a critical component for sustainable soil-transmitted helminth and schistosomiasis control. PLoS Negl Trop Dis. 2014:8(4):e2651.

51. Grimes JE, Croll D, Harrison WE, Utzinger J, Freeman MC, Templeton MR. The relationship between water, sanitation and schistosomiasis: a systematic review and meta-analysis. PLoS Negl Trop Dis. 2014;8(12):e3296.

52. Grimes JE, Croll D, Harrison WE, Utzinger J, Freeman MC, Templeton MR. The roles of water, sanitation and hygiene in reducing schistosomiasis: a review. Parasit Vectors. 2015;8(1):1.

53. Utzinger J, Raso G, Brooker S, De Savigny D, Tanner M, Ørnbjerg N, et al. Schistosomiasis and neglected tropical diseases: towards integrated and sustainable control and a word of caution. Parasitology. 2009;136(13):1859-74.

54. King $\mathrm{CH}$, Bertsch D. Historical perspective: Snail control to prevent schistosomiasis. PLoS Negl Trop Dis. 2015;9(4):e0003657.

55. Sokolow SH, Wood CL, Jones IJ, Swartz SJ, Lopez M, Hsieh MH, et al. Global assessment of schistosomiasis control over the past century shows targeting the snail intermediate host works best. PLoS Negl Trop Dis. 2016; 10(7):e0004794.

\section{Submit your next manuscript to BioMed Central and we will help you at every step:}

- We accept pre-submission inquiries

- Our selector tool helps you to find the most relevant journal

- We provide round the clock customer support

- Convenient online submission

- Thorough peer review

- Inclusion in PubMed and all major indexing services

- Maximum visibility for your research

Submit your manuscript at www.biomedcentral.com/submit 